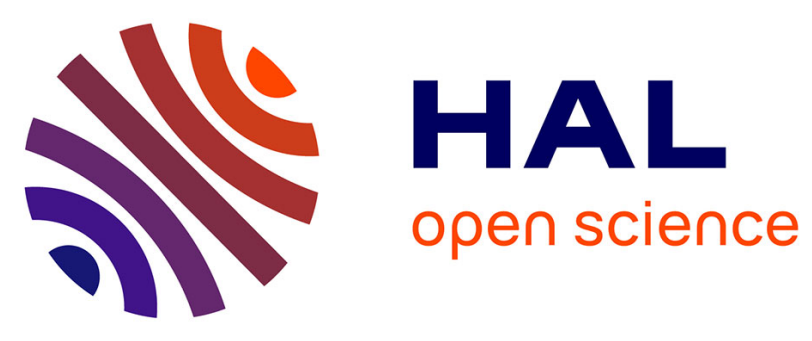

\title{
Outcome of gastrostomy in parkinsonism: A retrospective study
}

\author{
Clémence Marois, Maria del Mar Amador, Christine Payan, Lucette \\ Lacomblez, Anne-Marie Bonnet, Bertrand Degos, Jean-Christophe Corvol, \\ Marie Vidailhet, Nadine Le Forestier, Valérie Mesnage, et al.
}

\section{To cite this version:}

Clémence Marois, Maria del Mar Amador, Christine Payan, Lucette Lacomblez, Anne-Marie Bonnet, et al.. Outcome of gastrostomy in parkinsonism: A retrospective study. Parkinsonism \& Related Disorders, 2017, 10.1016/j.parkreldis.2017.06.012 . hal-01560102

\section{HAL Id: hal-01560102 https://hal.sorbonne-universite.fr/hal-01560102}

Submitted on 11 Jul 2017

HAL is a multi-disciplinary open access archive for the deposit and dissemination of scientific research documents, whether they are published or not. The documents may come from teaching and research institutions in France or abroad, or from public or private research centers.
L'archive ouverte pluridisciplinaire HAL, est destinée au dépôt et à la diffusion de documents scientifiques de niveau recherche, publiés ou non, émanant des établissements d'enseignement et de recherche français ou étrangers, des laboratoires publics ou privés. 


\section{Outcome of gastrostomy in Parkinsonism: a retrospective study.}

Clémence Marois $\mathrm{MD}^{1}{ }^{*}$, Maria Del Mar Amador $\mathrm{MD}{ }^{*}$, Christine Payan ${ }^{2}$, Lucette Lacomblez MD, PhD ${ }^{1,2,3,4,5,6}$, Anne-Marie Bonnet $\mathrm{MD}^{1}$, Bertrand Degos MD, PhD ${ }^{1}$, JeanChristophe Corvol MD, $\mathrm{PhD}^{1,3,4,5,6}$, Marie Vidailhet $\mathrm{MD}^{1,3,4,5,6}$, Nadine Le Forestier MD, PhD ${ }^{1,7}$, Valérie Mesnage $M D^{8}$ et David Grabli $M D, \mathrm{PhD}^{1,4,5,6}$

1 Assistance Publique Hôpitaux de Paris, Département de Neurologie, Hôpital Pitié-Salpêtrière, F75013, Paris, France

2 Assistance Publique Hôpitaux de Paris, Service de Pharmacologie Clinique, Hôpital Pitié-Salpêtrière, F-75013, Paris, France

3 Sorbonne Université, Université Pierre et Marie Curie Paris 06 UMR S 1127, F-75013, Paris, France 4 Institut National de Santé et en Recherche Médicale U 1127 and Centre d'Investigation Clinique 1422, F-75013, Paris, France

5 Centre National de Recherche Scientifique U 7225, F-75013, Paris, France

6 Institut du Cerveau et de la Moelle Epinière, F-75013, Paris, France

7 Université Paris Sud, Département de Recherche en Ethique ES3, F-91400, Orsay, France

8 Assistance Publique Hôpitaux de Paris, Service de Neurologie, Hôpital Saint-Antoine, Paris, France

*These authors contributed equally to this work

Dr David Grabli (Département de neurologie, Hôpital Pitié-Salpêtrière, AP-HP, Paris, France) carried out the biostatistical analysis.

Corresponding Author : Dr David Grabli, Département de neurologie, Groupe Hospitalier Pitié-Salpétrière, 75013 Paris, France; Tel: +33 (0) 1421624 61; email : david.grabli@aphp.fr 
Number of words in the body of the manuscript: 1624 (max 2000)

Number of words in the abstract: 238 ( $\max 250)$

Number of characters in the title: 55/62

Number of references: 14

Number of figures and tables: 1 figure, 1 table

Supplementary data: 2 supplementary tables (S1 et S2) and 1 supplementary method

E-mails of the co-authors: clemence.marois@aphp.fr , mariadelmar.amador@aphp.fr,

christine.payan@aphp.fr, lucette.lacomblez@aphp.fr, anne-marie.bonnet@aphp.fr,

bertrand.degos@aphp.fr, jean-christophe.corvol@aphp.fr, marie.vidailhet@aphp.fr,

$\underline{\text { nadine.leforestier@aphp.fr, valerie.mesnage@aphp.fr, david.grabli@aphp.fr }}$

\section{Authors' Contribution}

(1) Conception and design of the study, or, acquisition of data, or, analysis and interpretation of data,

(2) Drafting the article, or, revising it critically for important intellectual content,

(3) Final approval of the version to be submitted.

Clémence Marois : 1BC, 2AB, 3

Maria Del Mar Amador: 1BC, 2AB, 3

Christine Payan : 1A, 2B, 3

Lucette Lacomblez : $1 A B, 2 B, 3$

Anne-Marie Bonnet : 1B, 2B, 3

Bertrand Degos : 1B, 2B, 3

Jean-Christophe Corvol : 1B, 2B, 3

Marie Vidailhet : 1B, 2B, 3

Nadine Le Forestier : 1B, 2B, 3 
Valérie Mesnage : $1 A B C, 2 A B, 3$

David Grabli : $1 A B C, 2 A B, 3$

Role of funding source: This study received no specific funding 


\section{Abstract}

Objective: To investigate the indications and the outcomes of gastrostomy tube insertion in patients with parkinsonian syndromes

Methods: Consecutive patients with Parkinson's disease or atypical parkinsonism, seen in two French tertiary referral movement disorders centers, that received gastrostomy tube insertion (GTI) for feeding between 2008 and 2014 were included in this retrospective study. Data regarding clinical status, indications and outcomes were retrieved from medical files. The main outcome measure was survival duration following gastrostomy insertion according to Kaplan-Meier estimate. Cox analysis was also performed to identify factors associated with survival. Finally, we described short term and long term adverse effects occurring during the follow-up period.

Results: We identified 33 patients with Parkinsonism that received GTI during the study period. One patient was excluded from the analysis because of missing data. Among 32 patients, 7 (22\%) had Parkinson's disease and 25 (78\%) had atypical parkinsonism. The median survival following the procedure was 186 days (Cl 95\% [62-309]). In Cox model analysis, total dependency was the only factor negatively associated with survival (HR 0.1; 95 $\% \mathrm{Cl}[0.02-0.4], \mathrm{p}=0.001)$. Pneumonia was the most frequent adverse event.

Conclusion: In this sample of patients with parkinsonian syndromes, survival after GTI was short particularly in totally dependent subjects. Aspiration pneumonia was not prevented by GTI. A larger prospective study is warranted to assess the potential benefits of gastrostomy, in order to identify the most appropriate indications and timing for the procedure. 


\section{Introduction:}

Dysphagia is a common feature in patients with parkinsonian syndromes (PS) ${ }^{[1]}$ which include idiopathic Parkinson's disease as well as atypical neurodegenerative Parkinson syndromes. Dysphagia results in significant morbidity by interfering with medication administration, nutrition and fluid intake, and is associated with aspiration pneumonia - the most frequent cause of death in patients with PS ${ }^{[2]}$. For PS patients presenting with dysphagia, the decision regarding gastrostomy tube insertion (GTI) for feeding is challenging since to date, few studies have addressed the procedural risks and outcomes in this patient population ${ }^{[3-4]}$. In contrast, there are already established recommendations for GTI to maintain nutritional support in patients with amyotrophic lateral sclerosis (ALS) that present with severe dysphagia. ${ }^{[5-6-7]}$. Similarly, the guidelines are established for patients with advanced dementia which do not demonstrate a survival benefit, and consequently the procedure is not recommended. ${ }^{[8]}$

While the utility of GTI in PS patients remains unclear, our study aims to report the indications and outcomes for PS patients that received GTI at two French movement disorders centers, and to highlight any factors affecting these outcomes.

\section{Methods:}

All patients with a diagnosis of degenerative PS including idiopathic Parkinson's disease (IPD), multiple system atrophy (MSA), progressive supranuclear palsy (PSP), Lewy body dementia (LBD) or cortico-basal degeneration (CBD) that received GTI between January 2008 and December 2014 were identified from institutional databases at two movement disorders tertiary-care centers in Paris (see supplementary methods). Data was obtained retrospectively from anonymized routine medical charts and approval from our Institutional 
Review Board was waived. We also retrieved the number of PS patients seen at least once per year (caseload) in these centers. Informed consent for gastrostomy tube insertion was obtained from patients, or their relatives where the patient lacked capacity to provide informed consent at the time of gastrostomy insertion.

For each patient, data were extracted from medical records by two neurologists (CM and DG). Nutritional status was recorded according to the current French guidelines (see supplementary methods). Dependence was stratified in three levels based on the Schwab and England activities of daily Living Scale (level 1: completely independent (80-100\%), level 2: partially dependent, able to walk (40-70\%), level 3: totally dependent (0-30\%)). Speech was assessed according to item 18 of the Unified Parkinson Disease Rating Scale (UPDRS). Cognitive status was documented according to DSM IV criteria. Where possible, the indication for GTI from the clinician's perspective was determined from patient charts and was classified according to one or more of the following categories: undernutrition, impaired swallowing, aspiration pneumonia, inability to take drugs orally or unknown. Short-term adverse-events $(\mathrm{AE})$ were defined as complications that occurred during the gastrostomy procedure or the related hospital stay. AE occurring after hospital discharge were classified as long-term AE. For the survival study, data were censored on the 31th December 2015. Documented follow-up was available for all included patients for at least one year post-GTI. The main outcome measure was median survival time post-GTI, estimated by the KaplanMeier method. Cox proportional hazards regression analysis was performed to explore predictors of survival post-GTI. Covariates in the Cox regression were chosen among factors that might affect survival post-GTI in patients with a PS according to previous studies and our clinical judgment ${ }^{[9]}$. These covariates were age at gastrostomy, disease duration, atypical parkinsonism, presence of dementia, under-nutrition and inability to walk. Hazard 
ratios and $95 \%$ confidence intervals were computed for each variable. Secondary outcome measures included the median survival time from disease onset. A Kaplan-Meir estimate was computed only for the MSA group $(n=15)$ and could not be calculated for other disease subgroups due to small sample sizes (IPD $n=7, \operatorname{PSP} n=5, \operatorname{CBD} n=3$ and DLB $n=2$ ). A p-value less than 0.05 was considered statically significant for all analyses. Statistical analyses were performed using SPSS 24 (IBM).

\section{Results:}

From January 2008 to December 2014, between 4000 and 4500 PS patients were seen in clinic each year. Of these, approximately ten percent suffered from atypical parkinsonism. Thirty-three patients were identified as having received gastrostomy tube insertion (mean $4.7 \pm 1.3$ procedures each year). One patient was excluded from the study because of missing data. The general features of these patients are presented in table 1. The indication for GTI was explicit for 32 patients and is reported in table 1. Although undernutrition was noted in $72 \%$ of the patients, this feature was the specific indication from clinician's perspective in only $50 \%$. Other indications included swallowing impairment $(n=15,47 \%)$, aspiration pneumonia ( $n=11,34 \%)$ or inability to take drugs orally $(n=7,22 \%)$. The median survival following the procedure was 186 days (Cl 95\% [62-309]) according to Kaplan-Meier estimate (figure 1A). Cox regression analysis (figure 1B and supplementary table S2) showed that being totally dependent was the only independent factor associated with decreased survival (HR 0.1; $95 \%$ Confidence Interval [0.02-0.4], $p=0.001$ ). Two patients (6.25\%) died during their hospital stay due to aspiration pneumonia. Survival rate was $40.6 \%$ at one year and $34.4 \%$ at two years. During the follow up period, 22 patients (69\%) presented with at least one AE. Fourteen patients (46\%) developed aspiration 
pneumonia associated with acute pulmonary distress ( 9 patients), mechanical ventilation ( 3 patients) or tracheostomy (2 patients). Gastro-intestinal AEs, mainly gastrostomy related, accounted for $28 \%$ of the long term AEs (supplementary table S1). Median survival for MSA patients $(n=15)$ after disease onset was 10.9 [9-12.8] years as estimated by Kaplan-Meier method.

\section{Discussion:}

Despite the prevalence of swallowing disorders in patients with PS, very few studies have addressed the utility of GTI in this population. To our best knowledge, this is the first study that specifically describes the current use of gastrostomy in patients with PS, through the experience of two tertiary referral movement disorders centers.

Our study revealed that GTI was mainly utilized in patients with atypical parkinsonism. Of the seven patients with IPD, five presented with very advanced stages of disease and in the two other cases GTI was proposed specifically due to swallowing impairment albeit earlier in the disease course. Of course, the ability to facilitate therapeutic optimization of L-doparesponsive symptoms in IPD patients may have been an additional factor in the clinician's decision to perform GTI, even if not made explicit in the patient charts.

With respect to the primary outcome measure, our cohort demonstrated a strikingly short median survival of 6 months (186 days) following the procedure. This contrasts with ALS patients in two retrospective studies that demonstrated a median survival after GTI of 228 and 327 days respectively ${ }^{[10-11]}$. The short survival measured in our cohort may be partly explained by the fact that GTI was performed in patients at late stages of their disease course. At the time of GTI, 75\% percent of all patients were completely dependent. Furthermore, in the subgroup of MSA patients $(n=15$,$) gastrostomy was performed after$ median disease duration of 8.5 years which corresponds closely with overall median survival 
in MSA ${ }^{[12-13]}$. Naturally, no conclusions can be drawn as to an effect of GTI on survival owing to the absence of a control group. Identification of retrospective control patients in studies such as this (patients that declined gastrostomy) is difficult, as has been documented in other studies ${ }^{[7]}$. Furthermore, any attempt at prospective randomization in this particular context raises ethical concerns.

Total dependency before gastrostomy was found to be the only factor independently associated with survival. With small numbers of participants, our study was unlikely to be sufficiently powered to demonstrate associations between survival and other factors measured such as age, disease duration and the presence of dementia.

The most frequent complication recorded was aspiration pneumonia which occurred in half of the patients and lends weight to the prevailing view that GTI does not prevent aspiration. Interestingly, preventing aspiration pneumonia was the main indication from clinician's perspective for $34 \%$ of our patients.

Given that dysphagia in PS is common, the small number of GTI procedures undertaken in our study centers was surprisingly low in comparison with our large case load ${ }^{[1]}$. This may be either the result of clinicians' reluctance to propose GTI to this population given the uncertainties regarding the risks and benefits, patients or relatives' refusal of these invasive techniques or a combination of both. As emphasized previously, no guidelines endorse these procedures in PS patients. Furthermore, advance care planning is rarely discussed in relative slowly progressive diseases such as PS ${ }^{[14]}$.

Our study presents several limits, mainly due to its retrospective nature. Incomplete information was available about patients' nutritional status after gastrostomy, so we could not draw any conclusions regarding the nutritional efficacy of GTI in PS. Another shortcoming is the lack of quality-of-life data for patients and caregivers following 
gastrostomy which, in a setting where survival may not be the primary goal, is crucial to guide future clinical decisions. As randomization is not conceivable in this context, these complex issues should be at best addressed in future research with mixed methods (both quantitative and qualitative). Finally, this study, performed at two French movement disorders centers, may reflect a regionally-specific practice and thus, not be generalized to the broader PS population.

In conclusion, this study is one of the first to give specific insight into outcomes of GTI in PS. According to our results, ambulant patients are more likely to benefit from the procedure. A larger prospective study is warranted to assess the potential benefits of gastrostomy in terms of quality of life and nutritional efficacy, as well as to identify the most appropriate indications and timing for the procedure. This future research will enable clinicians and patients to discuss choices in an advance care planning setting with reference to an adequate evidence-base.

\section{$\underline{\text { References }}$}

[1] J. G. Kalf, B. J. M. de Swart, B. R. Bloem, and M. Munneke, "Prevalence of oropharyngeal dysphagia in Parkinson's disease: A meta-analysis," Parkinsonism Relat. Disord., vol. 18, no. 4, pp. 311-315, May 2012.

[2] U. Akbar, B. Dham, Y. He, N. Hack, S. Wu, M. Troche, P. Tighe, E. Nelson, J. H. Friedman, and M. S. Okun, "Incidence and mortality trends of aspiration pneumonia in Parkinson's disease in the United States, 1979-2010," Parkinsonism Relat. Disord., vol. 21, no. 9, pp. 1082-1086, Sep. 2015.

[3] Y. Yamazaki, K. Kobatake, M. Hara, M. Katagiri, and M. Matsumoto, "Nutritional support by 'conventional' percutaneous endoscopic gastrostomy feeding may not result in 
weight gain in Parkinson's disease," J. Neurol., vol. 258, no. 8, pp. 1561-1563, Aug. 2011.

[4] P. Sarkar, A. Cole, N.J. Scolding, C.M. Rice, "Percutaneous Endoscopic Gastrostomy

Tube Insertion in Neurodegenerative Disease: A Retrospective Study and Literature Review," Clin Endosc., 2016 Oct 13.)

[5] EFNS Task Force on Diagnosis and Management of Amyotrophic Lateral Sclerosis: et al., "EFNS guidelines on the clinical management of amyotrophic lateral sclerosis (MALS)-revised report of an EFNS task force," Eur. J. Neurol., vol. 19, no. 3, pp. 360-375, Mar. 2012. [6] R. G. Miller et al., "Practice parameter update: the care of the patient with amyotrophic lateral sclerosis: multidisciplinary care, symptom management, and cognitive/behavioral impairment (an evidence-based review): report of the Quality Standards Subcommittee of the American Academy of Neurology," Neurology, vol. 73, no. 15, pp. 1227-1233, Oct. 2009.

[7] P. S. Group, "Gastrostomy in patients with amyotrophic lateral sclerosis (ProGas): a prospective cohort study," Lancet Neurol., vol. 14, no. 7, pp. 702-709, Jul. 2015.

[8] D. Volkert et al., "ESPEN Guidelines on Enteral Nutrition: Geriatrics," Clin. Nutr. Edinb. Scotl., vol. 25, no. 2, pp. 330-360, Apr. 2006.

[9] L. P. Oosterveld, J. C. Allen Jr., G. Reinoso, S.-H. Seah, K.-Y. Tay, W.-L. Au, and L. C. S. Tan, “Prognostic factors for early mortality in Parkinson's disease," Parkinsonism Relat. Disord., vol. 21, no. 3, pp. 226-230, Mar. 2015.

[10] K. B. Russ, M. C. Phillips, C. Mel Wilcox, and S. Peter, "Percutaneous endoscopic gastrostomy in amyotrophic lateral sclerosis," Am. J. Med. Sci., vol. 350, no. 2, pp. 95-97, Aug. 2015.

[11] M. J. Pena, P. Ravasco, M. Machado, A. Pinto, S. Pinto, L. Rocha, M. de Carvalho, and H. C. Pinto, "What is the relevance of percutaneous endoscopic gastrostomy on the survival 
of patients with amyotrophic lateral sclerosis?," Amyotroph. Lateral Scler., vol. 13, no. 6, pp. 550-554, Oct. 2012.

[12] P. A. Low, S. G. Reich, J. Jankovic, C. W. Shults, M. B. Stern, P. Novak, C. M. Tanner, S. Gilman, F. J. Marshall, F. Wooten, B. Racette, T. Chelimsky, W. Singer, D. M. Sletten, P. Sandroni, and J. Mandrekar, "Natural history of multiple system atrophy in the USA: a prospective cohort study." Lancet Neurol., vol. 14, no. 7, pp. 710-719, Jul. 2015.

[13] J. J. Figueroa et al., "Multiple system atrophy: prognostic indicators of survival," Mov. Disord. Off. J. Mov. Disord. Soc., vol. 29, no. 9, pp. 1151-1157, Aug. 2014.

[14] B. M. Kluger et al., "Palliative care and Parkinson's disease: Meeting summary and recommendations for clinical research," Parkinsonism Relat. Disord., Jan. 2017.

Acknowledgments: We would like to thank Dr Richard Blazé for correcting the English and Dr Céline Louapre for statistical advice and helpful criticism.

\section{Figure legends}

\section{Table 1: Baseline characteristics of participants}

Figure 1: Survival functions for patients that underwent gastrostomy

Overall survival function (A) and survival according to functional status (B). Cox proportional hazard analysis suggest that functional status (i.e. being totally dependent at the time of gastrostomy insertion) was significantly associated with a decreased hazard of survival.

\section{Table S1: Clinical variables associated with hazard ratio of survival}

Table S2: Adverse events during the follow-up 


\begin{tabular}{|c|c|}
\hline Features & $\begin{array}{c}\text { Total population } \\
(\mathrm{n}=32)\end{array}$ \\
\hline Age, years $( \pm S D)$ & $67( \pm 9)$ \\
\hline Male gender, $\mathrm{n}(\%)$ & $18(56)$ \\
\hline Etiology of Parkinsonism, n (\%) & \\
\hline IPD & $7(22)$ \\
\hline MSA & $15(47)$ \\
\hline PSP & $5(16)$ \\
\hline CBD & $3(9)$ \\
\hline DLB & $2(6)$ \\
\hline Disease duration, years, med [IQR] & 8 [6-10] \\
\hline Autonomy status, n (\%) & \\
\hline Independent & $1(3)$ \\
\hline Partially dependant & $7(22)$ \\
\hline Totally dependant & $24(75)$ \\
\hline Communication status, $\mathrm{n}(\%)$ & \\
\hline Level 1 & 0 \\
\hline Level 2 & $3(9)$ \\
\hline Level 3 & $10(31)$ \\
\hline Level 4 & $19(59)$ \\
\hline Cognitive status, $n(\%)$ & \\
\hline No trouble & $8(25)$ \\
\hline $\mathrm{MCI}$ & $16(50)$ \\
\hline Dementia & $8(25)$ \\
\hline Under nutrition, $\mathrm{n}(\%)$ & $23(72)$ \\
\hline Comorbidity, n (\%) & \\
\hline Indications for GTI, $\mathrm{n}(\%)$ & \\
\hline Undernutrition & $16(50)$ \\
\hline Swallowing impairment & $15(47)$ \\
\hline Aspiration pneumonia & $11(34)$ \\
\hline Inability to take drugs orally & $7(22)$ \\
\hline Unknown & $1(3)$ \\
\hline GTI method, $\mathrm{n}(\%$ & \\
\hline Endoscopic & $27(82)$ \\
\hline Radiologic & $3(9)$ \\
\hline Unknown & $3(9)$ \\
\hline Length of hospitalization, days, med [IQR] & $10[8-16,5]$ \\
\hline
\end{tabular}

Table 1: Baseline characteristics of the patients.

Data are shown as mean ( \pm SD : standard deviation) or median [IQR : interquartile range $\left.25^{\text {th }}-75^{\text {th }}\right]$ or number $(\%)$.

IPD : Idiopathic Parkinson's disease; MSA: Multiple system atrophy; PSP: Progressive supranuclear palsy; CBD: Corticobasal degeneration; DLB: Dementia with Lewy bodies; GTI: Gastrostomy tube insertion. 
A

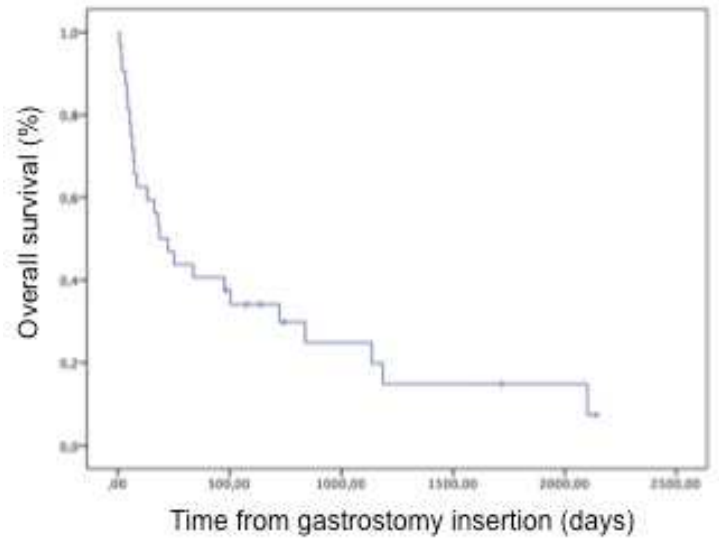

B

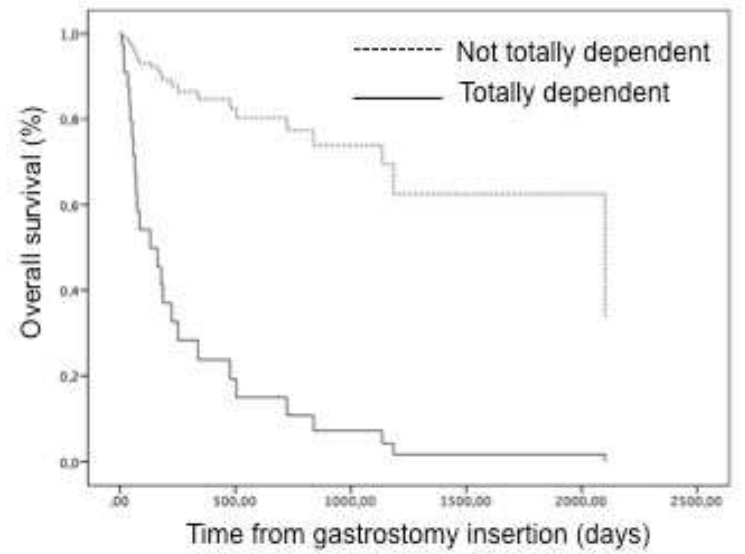




\section{Highlights}

-This is a retrospective study conducted on 33 patients

- We investigated the outcome of gastrostomy tube insertion in Parkinsonian syndromes.

- The median survival following the gastrostomy tube insertion was 6 months.

- Being totally dependent was associated with a shorter survival.

- Aspiration pneumonia is no prevented by gastrostomy tube insertion. 